\title{
Utilization of Infrared Thermography to Investigate Atmospheric Entry Aerothermodynamics of Space Vehicles at von Karman Institute
}

\author{
by C. O. Asma*, J. Thoemel*, S. Paris*, S. Tirtey* and O. Chazot ${ }^{*}$ \\ *Aeronautics and Aerospace Dept - von Karman Institute for Fluid Dynamics, Brussels, Belgium
}

\section{Abstract}

Space vehicles that make an entry through the atmosphere of a planet suffer tremendously because of extreme heating of the vehicle. The design of thermal protection systems for space vehicles involves multidisciplinary topics and is a very critical stage of space vehicles. The qualification of thermal protection systems on ground is very important for a safe space flight and the protection of critical payloads. At von Karman Institute, several ground facilities are used for the characterisation and qualification of thermal protection systems and materials. Infrared thermography is one of the most important measurement techniques used to monitor surface temperature and heat flux imposed on the thermal protection material, thus enabling the researchers to analyse the structural and thermal behaviour of tested materials.

\section{Introduction}

When a space vehicle is to make an entry into the atmosphere of the destination planet, it has to be protected from severe aerodynamic heating. The extremely high amount of kinetic and potential energy that the space vehicle has at the beginning of its atmospheric flight should have been completely transformed into thermal energy when the space vehicle finally lands down. Thermal protection system (TPS) materials are used to shield hypersonic aerospace vehicles from the severe aerodynamic heating encountered during atmospheric entry. Proper design of TPS is one of the most critical stages of the design of the space vehicles as it is indeed a complicated optimisation problem between many scientific restrictions. On one hand, the TPS has to be light enough, but on the other hand it has to guarantee the protection of the vehicle and its payloads from extreme temperatures. The aerodynamic constraints on the external shape of the space vehicle bring additional difficulty on designing the TPS.

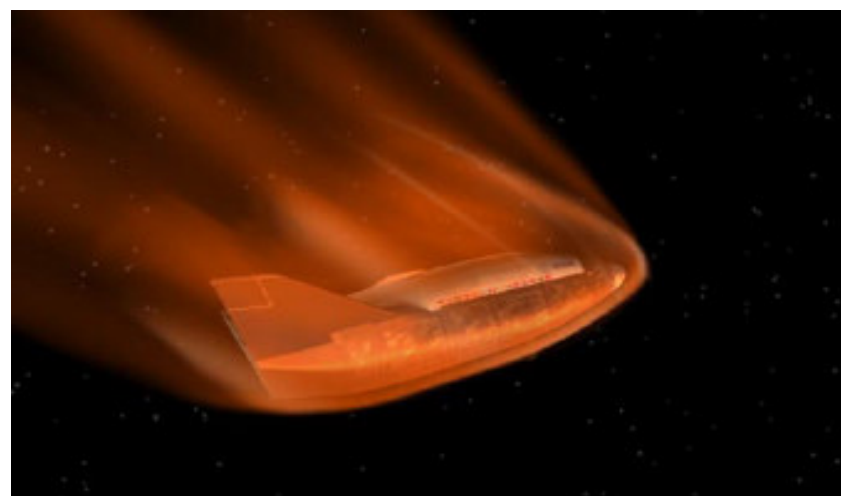

Fig. 1. Artistic view of the $X 38$ Crew Re-entry Vehicle (NASA / ESA)

The characterisation of the thermal protection material (TPM) is very important prior to the flight. Emissivity and catalycity at elevated temperatures are the two most important properties of the TPM [1]. The determination of emissivity and catalytic properties of TPS materials is a major issue for the aerospace vehicles. These properties strongly affect the heat transfer to the materials with up to a factor of two greater heat flux for a fully catalytic material compared to a non-catalytic material. Knowledge of TPS catalytic properties is extremely important for designing aerospace vehicles that have very stringent mass budget, for reusable launch vehicles the problem is even more critical. They require operating in a suitable ground facility with measurement techniques developed for high enthalpy flows. An appropriate methodology is also mandatory to allow for flight extrapolation.

For these reasons, many experimental investigations are carried out in ground facilities that are able to simulate the high enthalpy condition of atmospheric flights [2]. Performing tests under harsh thermal conditions is not easy. Suitable measurement techniques have to be applied carefully to be able to monitor the thermal and aerothermodynamic properties of the free-stream and the test model. Among several measurement techniques, infrared thermography is one of the most useful techniques to observe the temperature history of the test specimen. The fact that the surface temperature of the test specimen reaches values above $1000 \mathrm{C}$, radiative heat flux becomes significant, thus employment of infrared camera or pyrometers result in more precise temperature measurements compared to other techniques such as thermocouples. 


\section{High Enthalpy Facilities of von Karman Institute}

The experimental simulation of real flight situation in a laboratory is a very complex issue. The complete simulation of the aerodynamic and thermal loads encountered during re-entry flight is not possible within a single facility. New concepts of high-enthalpy facilities are being studied, such as the radiatively driven hypersonic wind tunnel using non-isentropic heating process [3] or very large scale arc-jet facility [4]. Those facilities approach better the reality but still address only one part of the trajectory and the main problem remain about the reacting flow produced by electrical discharge and not by shock waves as it occur in a real flight. At von Karman Institute, the atmospheric entry flight is simulated in two different facilities, one high-enthalpy facility (Plasmatron) and another facility (Longshot) that can simulate the high air velocity.

New paragraph: This is what the normal text looks like (Arial, 9 pt, justified).

\subsection{The Longshot Facility}

The VKI Longshot free piston tunnel (Fig. 1) is a short duration facility operating with nitrogen or carbon dioxide and designed for the attainment of very high Reynolds number hypersonic flows. It has a Mach 14 contoured nozzle of $0.43 \mathrm{~m}$ exit diameter and a 6 degree conical nozzle of $0.60 \mathrm{~m}$ exit diameter which can be used throughout the Mach number range from 15 to 20 using nitrogen and 10 to 15 using carbon dioxide. Typical Reynolds numbers at Mach 15 range from $5 \times 10^{6}$ to $20 \times 10^{6} / \mathrm{m}$.

A high precision incidence mechanism for pitch, roll, and yaw is mounted in the open-jet $4 \mathrm{~m}^{3}$ test section. Instrumentation includes a force/moment balance, accelerometers, thin-film and coaxial thermocouples for heat flux measurements, piezoresistive pressure transducers, and a Schlieren system; 64 channels of transient recorders with a $50 \mathrm{kHz}$ sampling rate are controlled by a PC.

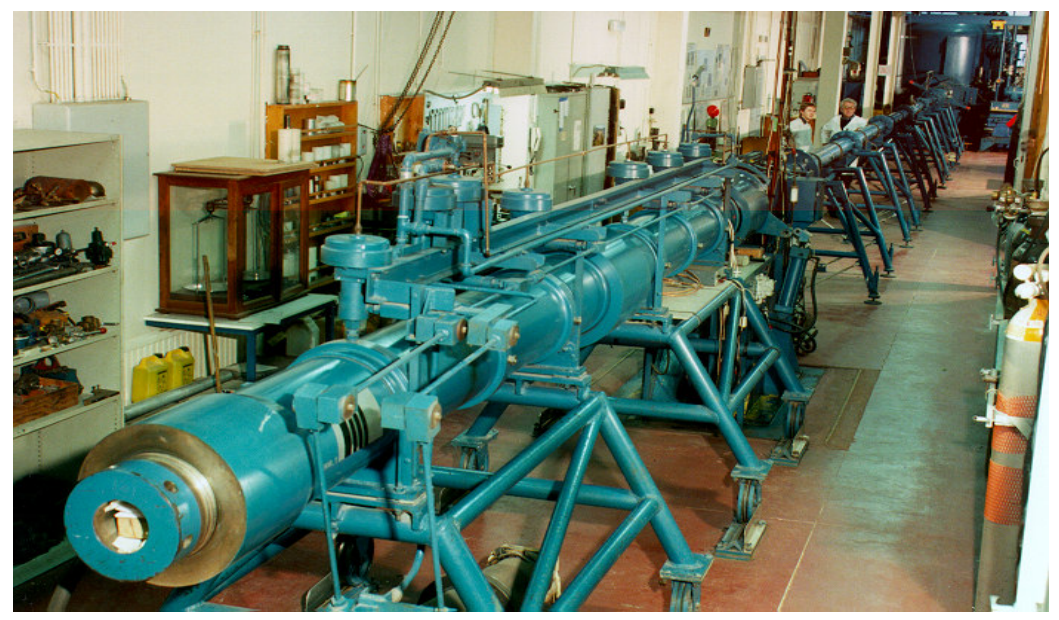

Fig. 2. VKI Longshot Facility

\subsection{The Plasmatron Facility}

The facility used at VKI for the testing is a Plasmatron-type using an Inductively Coupled Plasma (ICP) torch (Fig. 3). A sketch of the basic test configuration can be seen in Figure 4. VKI Plasmatron working principle and operation are presented in [5]

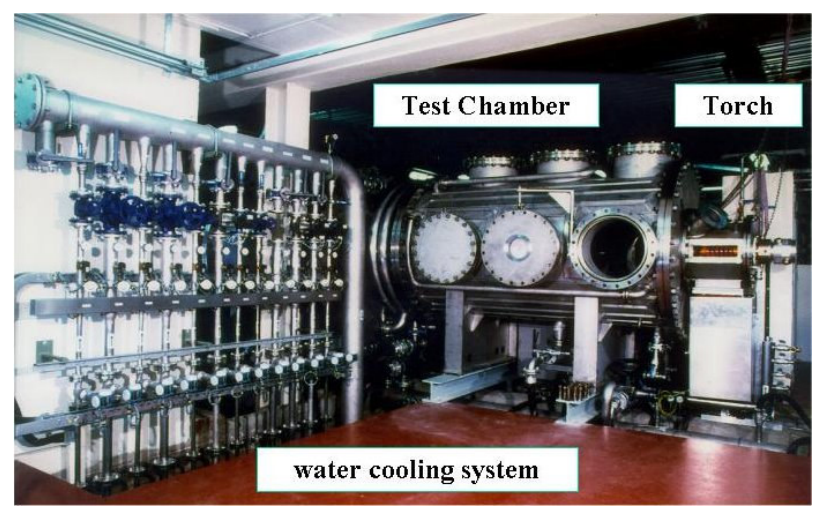

Fig. 3. The VKI Plasmatron facility. 


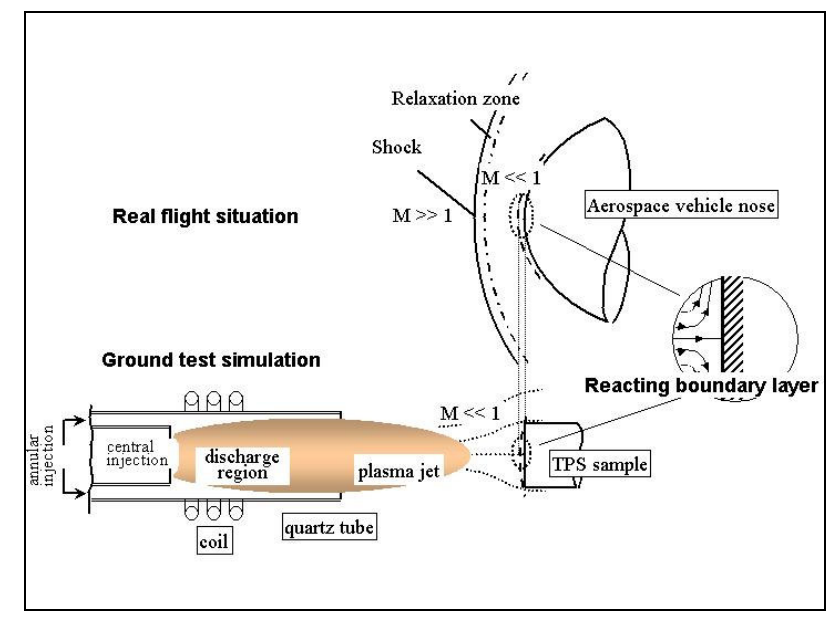

Fig. 4. Concept of local heat transfer simulation at VKI Plasmatron facility.

The main control parameters are the mass flow injected in the torch, the pressure in the test chamber and the generator power imposed. In the context of TPS testing and catalycity determination, it would be relevant to mention that it is an appropriate facility for those purposes. It allows testing in a subsonic plasma jet, where LTE conditions are more likely to be verified produced by an ICP torch, which provide chemical purity. This last point has been checked by spectroscopic measurements for the most powerful emission line of copper, silicon and iron [12]. It is equipped with an ICP torch of $160 \mathrm{~mm}$ diameter suited to samples as well as to full TPS tiles. The torch is mounted inside a support enclosure, which is fixed on a side of the test section, a $2.5 \mathrm{~m}$ long, $1.4 \mathrm{~m}$ diameter vessel equipped with multiple portholes and windows to allow maximal flexibility and unrestrained optical access for plasma diagnostic techniques. Inside the enclosure, the samples and probes are mounted on a fast-injection system.

The jet of plasma is collected at the outlet of the enclosure and cooled in the heat exchanger to a maximum temperature of $50^{\circ} \mathrm{C}$ to protect the vacuum plant from overheating damage. The vacuum plant consists of three volumetric vacuum pumps, which allow operating pressures between $1 \mathrm{hPa}$ and atmospheric pressure with a maximum flow rate of $3000 \mathrm{~m} 3 / \mathrm{h}$. A Roots pump can be inserted in the circuit to bring the pressure down. Exhaust gases are vented to the atmosphere through a stack.

The Plasmatron is equipped with a $1.2 \mathrm{MW}, 400 \mathrm{kHz}$, high-frequency generator of the new solid-state technology, using thyristors and MOS inverters instead of vacuum tubes. A huge closed circuit cooling system using de-ionised water protects all facility parts from melting due to the plasma heat, which is evacuated through three dry air coolers located on the roof. For air plasma, the facility is connected to the VKI compressed air supply. For test with $\mathrm{CO} 2$, rakes of bottle of compressed gas are used. The full facility is computer-controlled from a remote cabin.

Main measurement techniques applied at the Plasmatrin facility are temperature, heat flux and pressure measurements. For the characterization of the free-stream, laser diagnostics and spectroscopic techniques are utilized [7]. Infrared camera and two-color pyrometers are used to detect the surface temperature of the test specimen.

\section{Atmospheric Entry Aerothermodynamics}

The thermochemical non-equilibrium encountered in real flight is hard to duplicate in ground facilities. Only the conditions based on the local characteristics of the flow in the regions closest to the vehicle surface are considered. This is the basis of the Local Heat Transfer Simulation (LHTS) method, a hybrid numericalexperimental methodology. This local simulation methodology was developed at the Institute for Problems in Mechanics of Moscow (IPM). A detailed description can be found in [1, 8, 9] and it has been previously applied at the VKI $[10,11,12]$.

The LHTS is based on the pioneering work of Fay \& Riddell and Goulard on the similarity solution of the heat flux at the stagnation point of a chemically reacting boundary layer. It requires that the local conditions at the boundary layer edge around a stagnation point in the laboratory conditions and in real flight conditions are equal. For an accurate simulation, wall catalycity and emissivity should be the same in ground tests and in flight. The heat flux will be equal in the two cases if the boundary layer outer edge enthalpy He, chemical compositions, pressure $\mathrm{p}_{\mathrm{e}}$ and velocity gradient be are the same in the wind tunnel and in flight:

$$
\mathrm{H}_{\mathrm{e}}^{\mathrm{f}}=\mathrm{H}_{\mathrm{e}}^{\mathrm{g}} \quad \mathrm{p}_{\mathrm{e}}^{\mathrm{f}}=\mathrm{p}_{\mathrm{e}}^{\mathrm{g}} \quad \beta_{\mathrm{e}}^{\mathrm{f}}=\beta_{\mathrm{e}}^{\mathrm{g}}
$$

where subscript e refers to the boundary layer edge, superscript $f$ and $g$ refer to the flight and ground conditions respectively. Refer to Figures 4 and 5 for a schematic of the local simulation concept. 


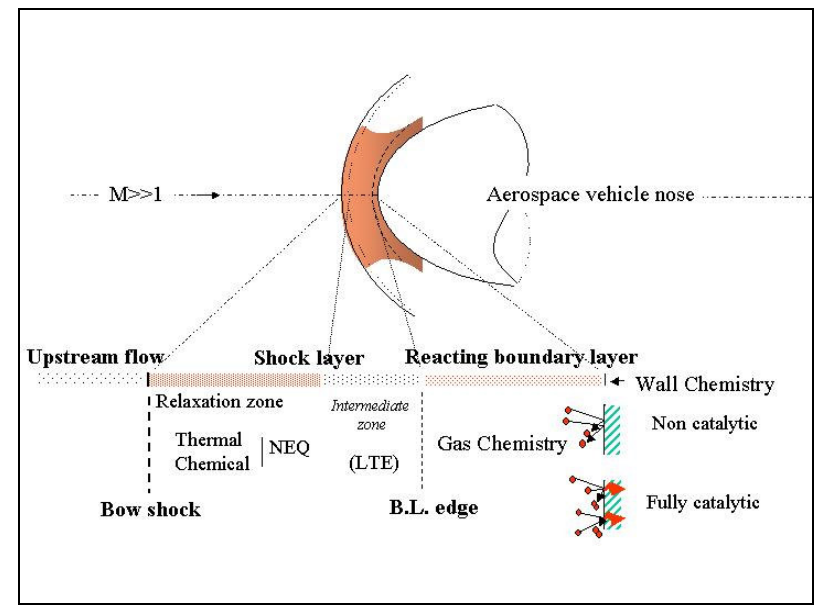

Fig. 5. Aerothermodynamics of real flight situation

For complete simulation of flight conditions, these three parameters should be duplicated in ground facilities. The problem is that only the stagnation pressure can be measured directly. To overcome this, two flow parameters are measured: the Pitot pressure and heat flux at the stagnation point. These are then related to the unknown enthalpy and velocity gradient at the boundary layer edge by means of an iterative process hence the hybrid numerical-experimental nature of the methodology [13]. The boundary layer edge characteristics are obtained via this iterative process. Measurements taken with a reference material (fully catalytic) are necessary to establish the properties of the flow in the laboratory conditions. For air, extensive experience has led to the use of copper as a good approximation to a high catalytic surface material.

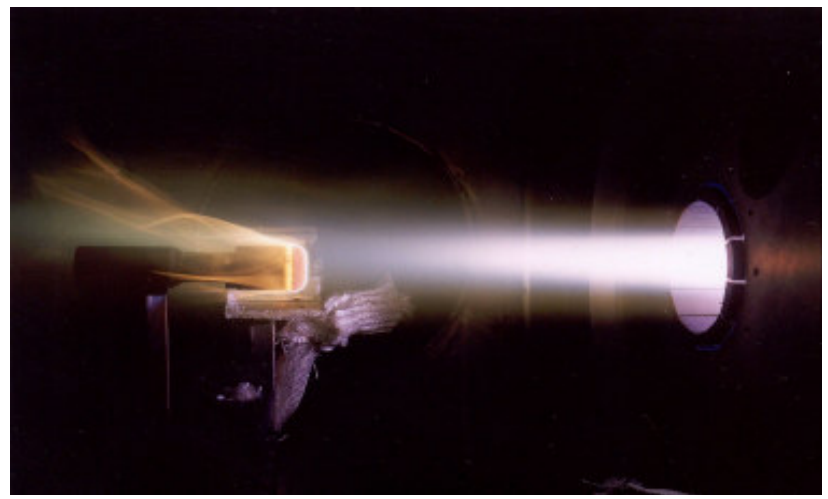

Fig. 6. Test of ablative material in the VKI Plasmatron facility

\section{Utilisation of Infrared Thermography for Atmospheric Entry Applications}

\subsection{Instrumentation}

\subsubsection{Two-Color Pyrometer}

Two two-color pyrometers (Raytek Marathon Series MR1SB with a temperature range of $700-1800^{\circ} \mathrm{C}$ and MR1SC with a temperature range of $1000-3000^{\circ} \mathrm{C}$ ) are used to measure the surface temperature of the sample during the test. A two-color pyrometer measures the IR emission from the surface at two different wavelengths that are fairly close to each other. If the emissivity, $\varepsilon$, of the material is considered constant over the two wavelengths, an absolute temperature measurement can be determined from a Planck's law analysis for a gray body. The acquisition speed is $1 \mathrm{~Hz}$. The pyrometer is calibrated using a blackbody radiation source, to take into account the effect of the window. The uncertainty is $\pm 10^{\circ} \mathrm{C}$. The pyrometers are used only for Plasmatron testing activities.

\subsubsection{Infrared Camera - FLIR Thermacam SC 3000}

A FLIR Thermacam SC3000 infrared camera is used during all experimental activities. This is a selfcooling infrared camera that measures and images the emitted infrared radiation from an object. It is used together with the ThermaCAM Researcher 2001 software (installed on a Microsoft Windows based CPU). The 
camera works in the range of $8-9 \mu \mathrm{m}$ wavelength. The infrared camera can measure temperatures varying between $-20 \mathrm{C}$ and $1500^{\circ} \mathrm{C}$ (assuming an emissivity of 1.0), however the accuracy varies as a function of the temperature range selected. Although the acquisition speed can be set as high as $750 \mathrm{~Hz}$ (at lower resolution) for Longshot tests, it acquires at lower frequency of $5 \mathrm{~Hz}$ for Plasmatron tests. The window that is used at Plasmatron is $\mathrm{Zn}$-Se and the window that is used at Longshot facility is germanium. The camera is not calibrated for this temperature range or for Plasmatron conditions.

\subsubsection{Sample Holder Probe}

For testing of thermal protection systems and materials at Plasmatron facility, a sample holder probe (Fig. 7 ) is used, which is composed of two coaxial tubes in which water circulates for cooling. At the front extremity, a support for the sample made of $\mathrm{SiC}$ or stainless steel is attached to the holder body by three metallic pins [13]. The sample is fixed in this support. Thermocouples are installed within the sample measuring temperature of the material at different locations during the test, to detect the back surface or internal temperature of the sample. The front face temperature is measured using pyrometers and/or infrared camera. The plasma flow is from right to left.

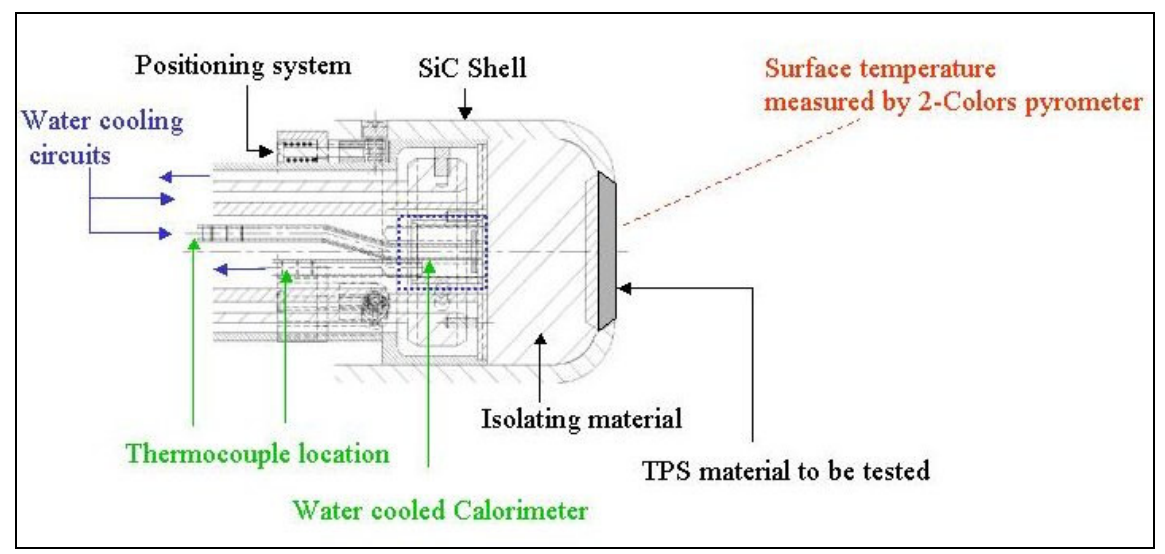

Fig. 7. Sample Holder Probe for Plasmatron Testing

\section{2. $\quad$ Plasma Flow Applications}

Thermal protection systems and materials are tested at Plasmatron facility at high heat flux conditions (up to $2500 \mathrm{~kW} / \mathrm{m}^{2}$ ) for different reasons:

- To measure the efficiency of the thermal protection system

- To observe the behavior of the thermal protection material to chemical reactions under high heat flux

- To measure the catalycity and emissivity of the thermal protection material at high temperature and low pressure

- To test the reusability of the thermal protection system

- To characterize the materials and to perform flight qualification tests.

For all these purposes, front face temperature measurement is a very critical aspect of testing, which can be performed by infrared thermography in a non-intrusive way. Tests can be performed either at steady state or under transient heat flux conditions, depending on the purpose. The history of front face temperature is always an important input for the analysis of the thermal protection material. As an example, Figure 8 shows four consecutive infrared images of an ablative material being tested at $500 \mathrm{~kW} / \mathrm{m} 2$ heat flux. The erosion that the ablative material experiences can easily be seen, as well as the temperature map on the material at different instants.

It is important to know the behavior of thermal protection materials at different temperatures. Because of the existence of many species, ions and free electrons in the plasma flow, various chemical reactions can occur inside the boundary layer. These reactions (as well as the population of different species) and the nature of the flow are temperature dependant. Thus, the same material can show different behaviors at different temperatures. Figure 9 shows the color change of metallic PM1000 materials; a virgin sample at the left and samples tested at $1150 \mathrm{~K}, 1310 \mathrm{~K}$ and $1460 \mathrm{~K}$ respectively $[15,16]$. Infrared thermography comes as a very handy and reliable tool not only to determine the exact surface temperature of the tested sample, but also to adjust the power setting of the facility to achieve a pre-determined surface temperature. 

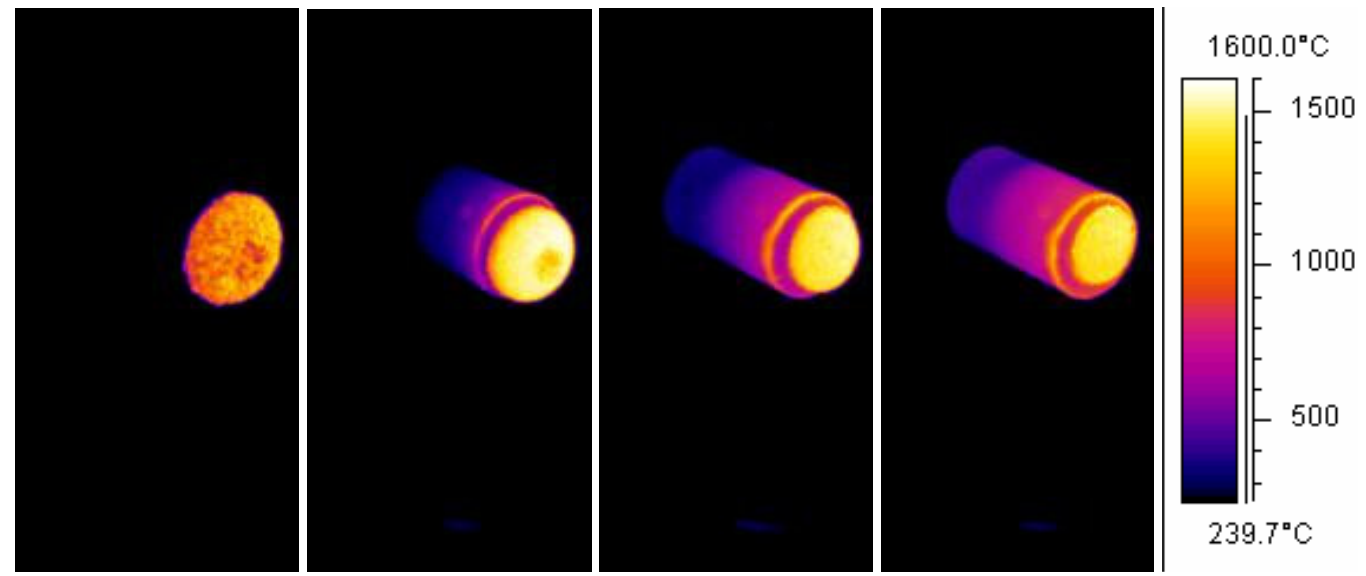

Fig. 8. Ablation during Plasmatron Testing, infrared images at different times

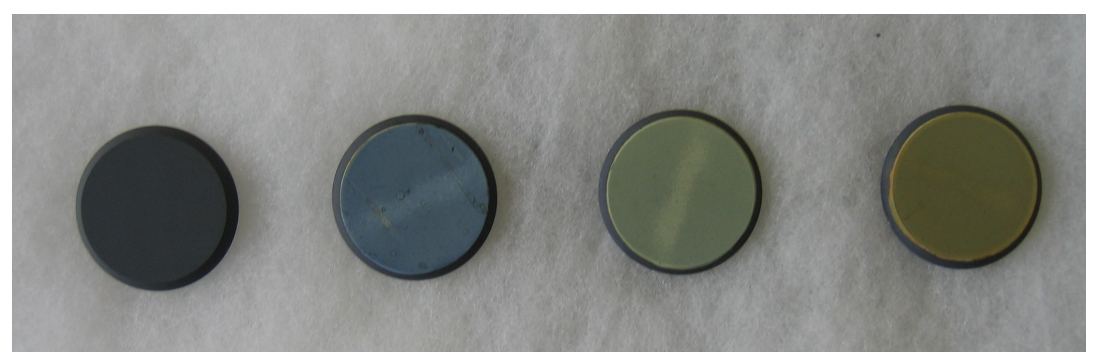

Fig. 9. Metallic PM1000 samples tested at different temperatures

Infrared thermography is frequently used in the flight qualification tests of thermal protection systems. One example is the TPS of the FOTINO vehicle of YES2 project [17]. Figure 10 shows a picture of the spherical capsule with its TPS being tested in Plasmatron facility (left) with an infrared image taken during the same test (right). After having tested this material several times at different steady state conditions to characterize its thermal properties, a final series of tests have been performed under more realistic transient heat flux conditions. The expected stagnation point heat flux data is extracted from the calculated flight trajectory of the capsule. The Plasmatron facility is programmed to follow the heat flux trajectory, so that the realistic heat flux can be applied on the model and possible thermal shocks can be observed.

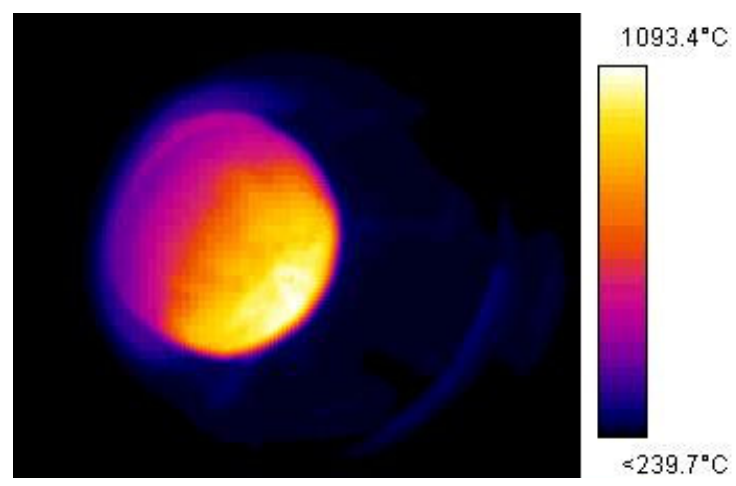

Fig. 10. Scaled down FOTINO model of YES2 during heat flux trajectory simulation; IR image

During these tests, the pyrometers and the infrared camera are employed at the same time. As the twocolor pyrometer results are independent of the emissivity of the material, the infrared camera results can be corrected by imposing a specific emissivity so that the two temperature curves agree with each other. An example of this operation is shown in Figure 11, where the infrared camera assumes an emissivity of 0.74 . This quick and easy estimation of the order of magnitude of material's emissivity has to be corrected by taking the transmissivity of the window in infrared range into account. 


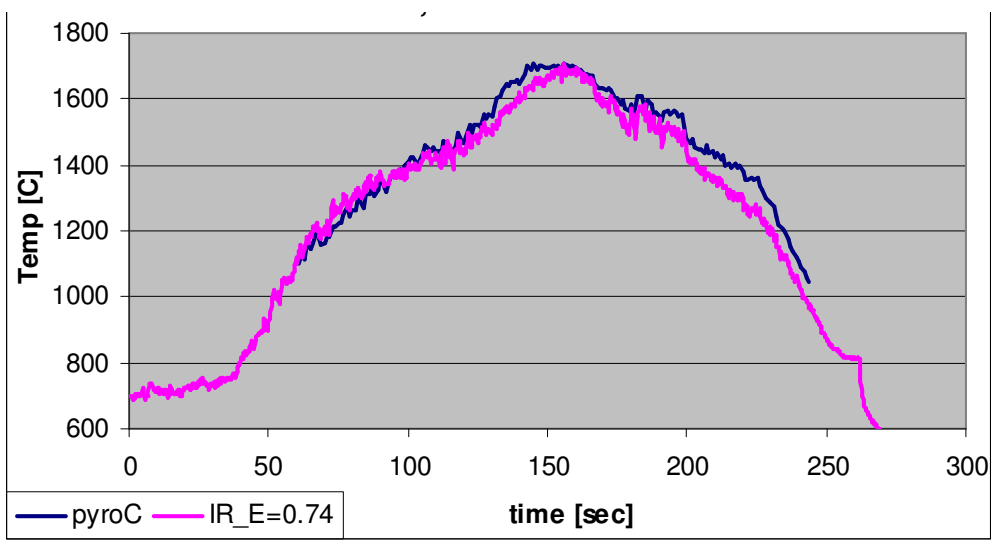

Fig. 11. Temperature variation on stagnation point; pyrometer data (pyroC curve) vs emissivity corrected infrared camera data (IR_E=0.74 curve)

\subsection{Hypersonic Flow (Longshot) Applications}

Aerodynamic heating, being one of the most critical design parameters when atmospheric reentry is considered, can drastically be increased when the boundary layer is triggered from laminar to turbulent flow. This transition of the boundary layer nature can be influenced by many factors, among which one of the most important is the presence of discontinuities on the surface along which the boundary layer has developed. This and other phenomena related to laminar to turbulent transition are investigated at the hypersonic facilities of VKI, mainly at Longshot facility, using infrared thermography. For this purpose, flat plate or scaled down flight models are equipped with isolated or distributed roughness elements. These wind tunnel models are then tested at hypersonic facilities by employing an infrared camera to detect whether transition to turbulence occurs or not. Figure 12 shows infrared images of two flat plate models, one with an isolated roughness elements and the other one with multiple roughness elements tested under Mach 6 flow. The flow is from right to left. In both pictures, the wakes behind the roughness elements are clearly visible. However, for the isolated roughness case, with the widening of the wake, an increment of temperature is also visible, which indicates turbulent flow; whereas for the multiple roughness elements case, there is no increase of temperature as one moves downstream. The widening of the wake is caused by stable vortices, which do not end up in turbulence.
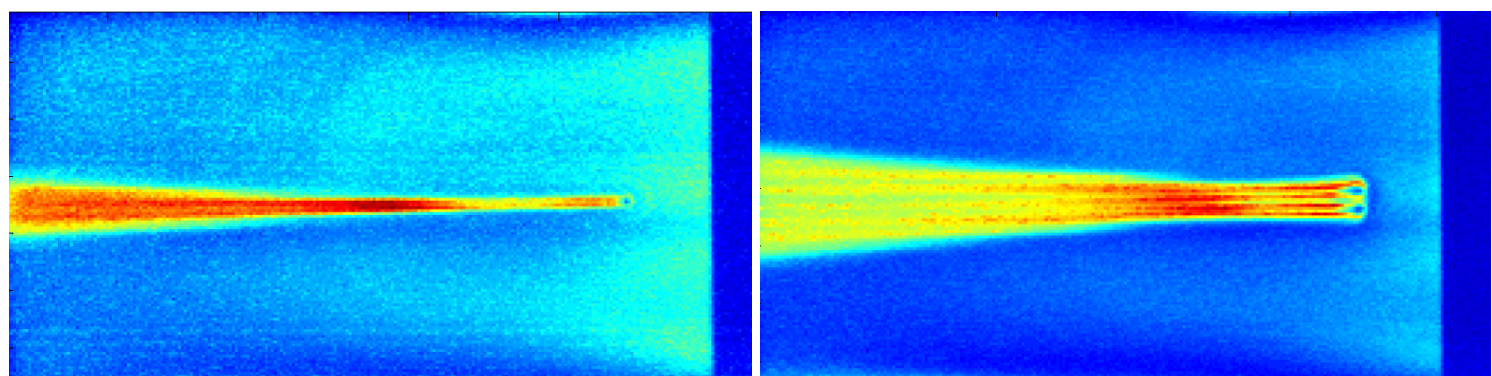

Fig. 12. Infrared images of flat plates with isolated (left) and multiple (right) roughness elements, Mach 6.

Transition to turbulence at hypersonic speeds is a very complicated phenomenon and there are many parameters that affect laminar to turbulent transition. The main parameters are Reynolds number, Mach number, boundary layer thickness, roughness element geometry and height, number of roughness elements, distribution of roughness elements, nature of roughness elements (perturbation, waviness, positive or negative step, cavity, etc), flow static temperature, wall temperature, angle of attack, etc... All these parameters are studied experimentally at Longshot facility. One example is the studies performed on EXPERT Vehicle [16, 18], where either distributed roughness elements are placed on the nose or isolated roughness elements are placed on the nose-cone junction of the vehicle. Figure 13 presents different infrared images taken at high frequency $(750 \mathrm{~Hz})$ at low (left images) and high (right images) Reynolds numbers and using roughness elements at different heights. For convenience, a picture of the EXPERT vehicle is also attached to this Figure. Once the infrared images are obtained after such a test, as the temperature at every point and at any time is known, it is possible to calculate the heat transfer rate. The non-dimensional heat transfer (Stanton number) is then compared with the theoretical values for laminar and turbulent flow, hence allowing the researchers to decide whether the flow is triggered to turbulence or not. As modeling transition to turbulence is a very complicated issue, some transition criteria are developed by researchers. These criteria are all geometry dependent, so it is important to choose or develop a relevant criterion for the vehicle and the mission that is studied. Figure 14 presents the PANT correlation [19] as an example, with experimental data collected on EXPERT vehicle at VKI's hypersonic facilities [18]. According to this correlation, 
the transition line is calculated based on the parameters of Reynolds number, momentum thickness of the boundary layer, ratio of boundary layer edge temperature to wall temperature and thickness of the roughness element. Any experimental point that is located on the right side of the curve is supposed to result in turbulent, whereas any experimental point that lies at the left of the curve is supposed to remain laminar.
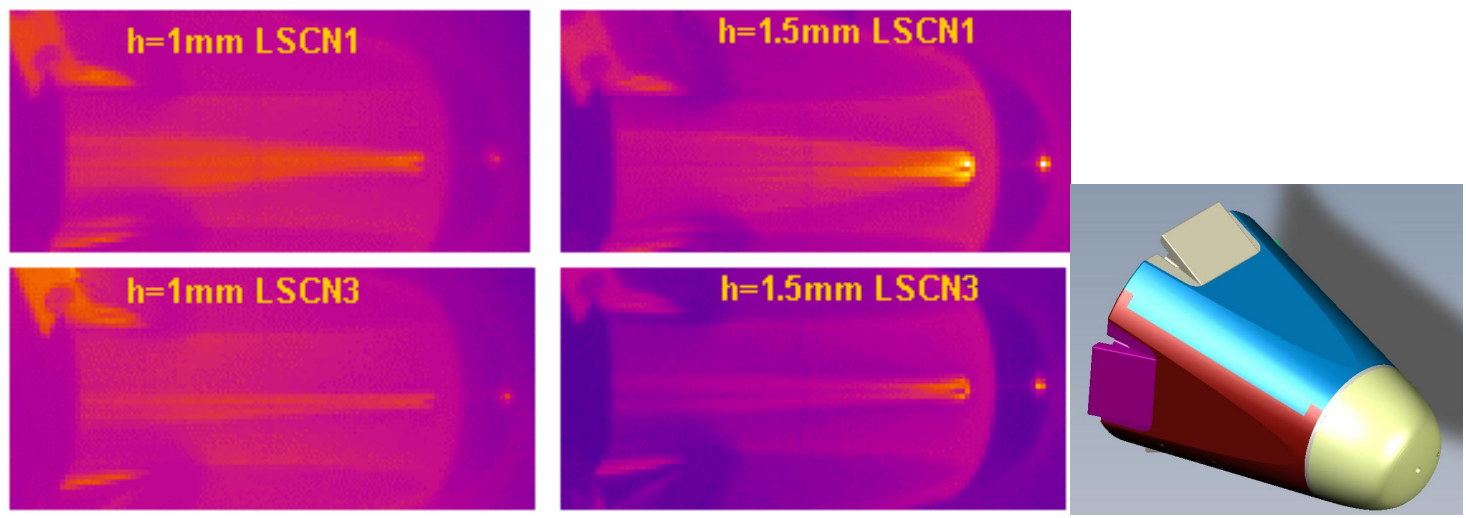

Fig. 13. Infrared images of EXPERT model (right) with roughness elements tested at Longshot, Mach 14.

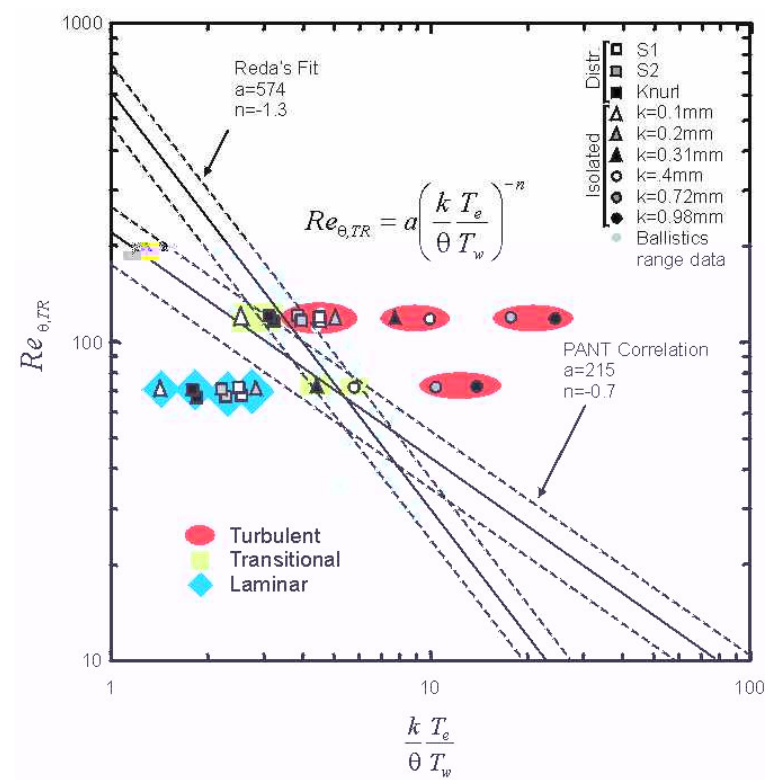

Fig. 14. PANT Correlation: Results for distributed and isolated roughness tests

Infrared thermography is not only used for detecting laminar to turbulent transition, but also for understanding the flow topology. For high-speed flows, the aerodynamic topology of the flowfield usually leaves a temperature signature on the surface of the test model, provided that the wind tunnel model is made of a material which is not highly conductive. By looking at the infrared image, it might be possible to detect vortices, stagnation points, flow separations, reverse flow regions, reattachments, shock - boundary layer interactions, etc... An example is shown on Figure 15, where the infrared image shows the effect of a Pitot rake probe installed at the aft of the EXPERT vehicle. The Pitot rake probe is also shown bigger on the same figure, for convenience. This test is performed to check if the presence of the probe significantly affects the flowfield around the flaps.
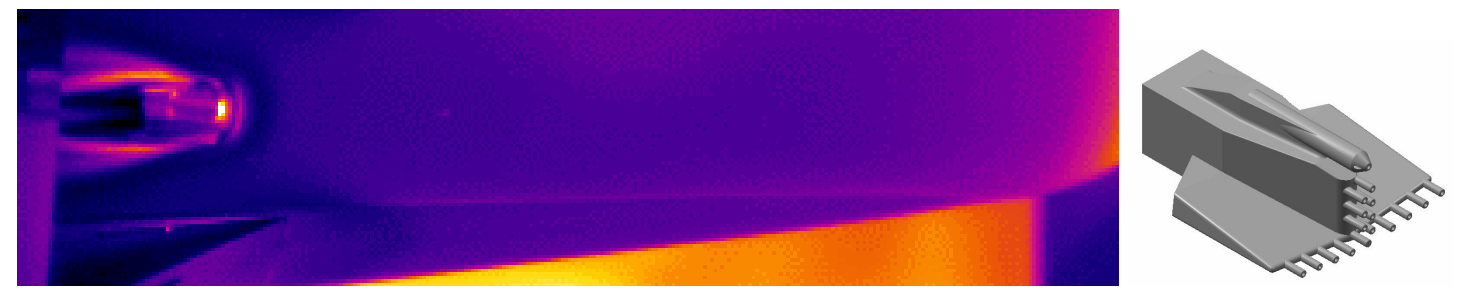

Fig. 15. Pitot rake probe on EXPERT model, tested at Longshot, Mach 14. 


\section{Conclusion}

Aerodynamic heating is one of the most critical design parameters when atmospheric entry of space vehicles is considered. A space vehicle enters the atmosphere at a very high velocity, in the order of several kms per second. As the atmosphere gets thicker, the friction between the vehicle and the atmospheric gas heats up the gas, causing it to become plasma. Several important interactions between the vehicle and the surrounding atmosphere have to be studied at ground test facilities for the safety of the vehicle and also for the optimization of the vehicle design. The stagnation point aerodynamic heating and the interaction between the thermal protection system and the chemically reacting plasma environment are the most important ones. But other than this, the aerodynamics and aerothermodynamics of hypersonic flow is a discipline that has to be analyzed and understood in depth for a successful return of a space vehicle. For all these purposes, many experimental activities are performed in the hypersonic and high-enthalpy facilities of von Karman Institute. As the aerothermodynamics is the main concern, infrared thermography is the main measurement technique used during such experimental activities. Thanks to infrared thermography, the temperature map of the test model can be obtained any time in a non-intrusive way. Processing of the data obtained from infrared thermography would help in carrying out research on the characterization and qualification of thermal protection systems, laminar to turbulent transition and determining the flow topology.

\section{REFERENCES}

[1] Kolesnikov, A. Conditions of simulation of stagnation point heat transfer from a high enthalpy flow. Izvestiya Rossiiskoi Akademii Nauk, Mekhanika Zhidkosti I Gaza, Vol. 1, January-February 1993, pp 172-180.

[2] Kolesnikov, A. Extrapolation from high enthalpy tests to flight based on the concept of LHTS. Belgium. RTOVKI Special course. Measurement Techniques for High Enthalpy and Plasma Flows, October 1999.

[3] Miles, R.B., Brown, G.L., Lempert, W.R., Yetter, R., Williams, G.J.Jr., Bogdonoff, S.M., Natelson, D., Guest, J.R. Radiatively driven hypersonic wind tunnel, AIAA Journal, 33(8), August 1995, p. 1463-1470.

[4] Caristia, S., De Fillipis, F., SCIROCCO Project a major plasma wind tunnel for the year 2000, proceeding of International Symposium on Atmospheric Re-entry Vehicles and Systems, Arcachon (F), 16-18 May 1999.

[5] Bottin, B., Carbonaro, M., Decré, M., Mazauric, S., Novelli, A. Design of a new inductively-coupled plasma wind tunnel for reentry material testing at the von Kármán Institute, Wind tunnels and wind tunnel test techniques, Cambridge (UK), 1997.

[6] Muylaert, J.M., et al, "Flight Measurement Technique Developments for EXPERT, the ESA In-flight Aerothermodynamic Research programme", 55th International Astronautical Congress, Vancouver, Canada, 2004.

[7] D. Fletcher, M. Playez. Characterization of Supersonic and Subsonic Plasma Flows. AIAA 2006-3294.

[8] Kolesnikov, A.F. : Combined Measurements and Computations of High Enthapy and Plasma Flows for Determination of TPM Surface Catalycity. Belgium. RTO-VKI Special Course. Measurement Techniques for High Enthalpy and Plasma Flows, October 1999.

[9] Kolesnikov, A. Extrapolation from high enthalpy tests to flight based on the concept of LHTS. Belgium. RTOVKI Special course. Measurement Techniques for High Enthalpy and Plasma Flows, October 1999.

[10] De la Llave Plata, M. Analysis and application of a methodology for the determination of TPS material catalycity. June 200. VKI PR 2000-04.

[11] García Muñoz, A. Catalycity effects in plasmatron tests. June 2001. VKI PR 2001-12.

[12] Vancrayenest, B. Determination de catalycite des materiaux TPS en conditions de reentree atmospherique dans le plasmatron de I'IVK. September 2001. VKI SR 2001-32.

[13] Chazot, O.; Paris, S.; Collin, P.; Bickel, M.; Ullman, T. TPS testing and catalycity determination in the VKI Plasmatron facility. 3rd Internation Symposium Atmospheric Reentry Vehicles and Systems, Arcachon, France, March 24-27, 2003

[14] H. S. Carslaw, and J.C. Jaeger. Conduction of heat in solids. Oxford University Press (1959).

[15] Asma, C. O., Chazot, O. Trajectory Simulation and Catalycity Determination for EXPERT Vehicle. 5th European Symposium on Aerothermodynamics for Space Vehicles, November 8-11, 2004, Cologne, Germany.

[16] F. Cipollini, J. M. Muylaert, European Activities on Advanced Flight Measurement Techniques for Hypersonic Space Vehicles, AIAA 2006-3832, 25th AIAA Aerodynamic Measurement Technology and Ground Testing Conference, San Francisco, California. 5 - 8 June 2006.

[17] Asma, C. O., De Pascale, F., Kruijff, M. Heat Shield Qualification for the SpaceMail Re-Entry Capsule "Fotino" in the VKI Plasmatron. AIAA-2008-6561. AIAA Atmospheric Flight Mechanics Conference and Exhibit. 18 - 21 Aug 2008, Hawaii Convention Center and Hilton Hawaiian Village, Honolulu, Hawaii.

[18] Paris, S., Fletcher, D., Cerignat, L., Garzon, A. Roughness Induced Transition for Flight Experiments. $4^{\text {th }}$ International Symposium, Atmospheric Reentry Vehicles \& Systems, Arcachon, France. 21 - 23 March 2005.

[19] Reda, D. C. Review and Synthesis of Roughness-Dominated Transition Correlations of Reentry Applications. Journal of Spacecrafts and Rockets, Vol. 39, Iss. 2, pp. 161-167. 2002. 
http://dx.doi.org/10.21611/qirt.2008.07_01_11 